\title{
GÊNERO, SEXUALIDADE E A IMPORTÂNCIA DE PRÁTICAS PEDAGÓGICAS INTERCULTURAIS
}

Carla Silva Machado ${ }^{1}$

\section{Resumo}

O presente artigo objetiva salientar a importância das práticas pedagógicas interculturais na perspectiva apresentada por Fleuri (2003) e Candau $(2015,2011)$. Faremos nosso recorte nas questões que envolvem Gênero e Educação, a partir da percepção de que esta tem sido uma temática bastante discutida. O tema teve destaque no ano de 2015 , em que se discutiu amplamente o Plano Nacional de Educação (PNE) para os próximos dez anos. Ele ganhou destaque em função de posições bastante antagônicas acerca de sua inclusão no PNE. Neste artigo, daremos ênfase às práticas midiáticas na educação, abordando especificamente o cinema e as discussões de gênero e sexualidade no âmbito escolar. Para contribuir com a discussão contaremos com autores que tratam da relação entre comunicação e educação, tais como Orozco (1997), Martín-Barbero (2013), Bacega (2009) e outros. Na discussão, envolvendo cinema, educação, gênero e sexualidade, traremos Louro (2014, 2013, 2008), Duarte (2009), Ferrari e Castro (2012), além de outros estudiosos que abordam as relações entre mídia-sexualidade-gênero-educação.

Palavras-chave: Educação Intercultural; Mídia; Sexualidade; Gênero; Cinema

Não se ia ao cinema para sonhar; ia-se para aprender. (MARTÍNBARBERO, 2013, p. 235)

\footnotetext{
1 Doutoranda em Educação pela PUC/Rio. Bolsista de doutorado do CNPq. Mestre em Educação pela Universidade Federal de Juiz de Fora. Endereço: Rua Padre Anchieta, 165, apto. 201. CEP: 36016440. Bairro São Mateus - Juiz de Fora -MG - Brasil; Endereço eletrônico: carlasingular@ yahoo.com.br
} 


\section{INTRODUÇÃO}

Este artigo objetiva discutir as práticas pedagógicas interculturais que visam promover a educação levando-se em conta a alteridade, ou seja, práticas que caminham para a diversidade de pensamentos, ideias e modos de ser. Para isso, propomos um recorte na temática do gênero e da sexualidade e no desenvolvimento dessa temática a partir de práticas midiáticas, dando ênfase ao cinema.

Neste sentido, o texto está dividido em 5 seções, quais sejam, esta primeira que trata da apresentação e da estrutura do artigo. A seção 2, intitulada Educação Intercultural Crítica, que apresenta a perspectiva de interculturalidade a qual defendemos e que perpassa o campo da educação, mas também está presente no campo da cultura e das relações sociais. Na seção 3, discutimos as questões envolvendo Gênero, Sexualidade e Educação.

A seção 4 apresenta as relações entre Cinema, Educação e Gênero, foco principal deste artigo. A seção 5 destaca as Considerações Finais, na qual abordamos que o cinema na sala de aula pode caminhar numa perspectiva intercultural e feminista, visto que pode servir para problematizar as questões de gênero e equidade.

\section{EDUCAÇÃO INTERCULTURAL CRÍTICA}

Vale ressaltar que, no desenvolvimento deste trabalho, teremos como premissa a Educação intercultural na perspectiva crítica que, segundo Fleuri (2003, p. 17):

[...] o trabalho intercultural pretende contribuir para superar tanto a atitude de medo quanto a de indiferente tolerância ante o "outro", construindo uma disponibilidade para a leitura positiva da pluralidade social e cultural. Trata- se, na realidade, de um novo ponto de vista baseado no respeito à diferença, que se concretiza no reconhecimento da paridade de direitos.

Neste mesmo sentido, Candau (2011, p. 27) afirma que:

A perspectiva intercultural quer promover uma educação para o reconhecimento do 'outro', para o diálogo entre os diferentes grupos sociais e culturais. Uma educação para a negociação cultural, que enfrenta os conflitos provocados pela assimetria de poder entre os diferentes grupos socioculturais nas nossas sociedades e é capaz de favorecer a construção de um projeto comum, pelo qual as diferenças sejam dialeticamente integradas. A perspectiva intercultural está orientada à construção de 
uma sociedade democrática, plural, humana, que articule políticas de igualdade com políticas de identidade.

Ainda, segundo Fleuri (2003), o campo da Intercultura é um campo de "debate entre as variadas concepções e propostas que enfrentam a questão da relação entre processos identitários socioculturais diferentes” (p. 22). Neste campo, segundo o autor, articulam-se o reconhecimento das identidades de caráter étnico, de gênero, de geração, de diferenças físicas e mentais.

Candau (2015) sugere que a educação escolar precisa ser reinventada, visto que há algum tempo não é um espaço que estimule uma boa convivência entre professores e alunos. Ela relata que os problemas da escola partem desde a universalização do ensino, perpassando questões de qualidade educacional, violências físicas e simbólicas na escola que atingem tanto professores quanto alunos. Por isso, a sugestão da autora é de reinventar a educação escolar para que esta passe a ser significativa para as crianças e para os jovens. Candau (2015) nos lembra que, por muito tempo, a função da escola, assim como da sociedade, foi padronizar os comportamentos, ignorando qualquer diferença, porém, a sociedade não é mais a mesma e a escola precisa mudar para atender às novas demandas. Para a autora, só há uma maneira de transformar a educação escolar radicalmente levando-se em conta a diversidade: "transformar a diversidade conhecida e reconhecida em vantagem pedagógica” (2015, p. 111).

Ao introduzir o tema da Didática, a autora traça um histórico da produção da área no Brasil, deixando evidenciar o marco da década de 1980, em que se deu a convergência em torno da perspectiva crítica. A autora levanta que, a partir da década de 1990, há um nó no campo da Didática, pois para alguns teóricos uma ampliação em torno da dimensão cultural poderia enfraquecer a dimensão social, segundo ela, um pensamento não enfraquece o outro, apenas articula "as diferentes dimensões de ação educativa" (CANDAU, 2015, p.113). Para Candau (2015), é inevitável associar as questões sociais à perspectiva intercultural, visto que o reconhecimento das diversas identidades perpassou, durante muito tempo, pelos movimentos sociais, quais sejam, movimento negro, movimento feminista, movimento LGBTT e outros. Neste sentido, a autora argumenta que os movimentos identitários e sociais formam um eixo fundamental e, por isso, não é possível separá-los. Nesta perspectiva, por exemplo, ao tratar das questões femininas, o campo da Didática levará em conta as questões que envolvem o trabalho feminino, a classe social, étnica da mulher, dentre outros elementos, ou seja, as várias identidades da mulher serão levadas em conta, por isso a formação de um eixo fundamental. 
Ao abordar a educação numa perspectiva intercultural, Candau (2015) apresenta algumas questões envolvendo as palavras multiculturalismo e interculturalidade, para a ela o multiculturalismo é polissêmico e isso permite inúmeras interpretações que vão desde as mais radicais, de esquerda, até as mais conservadoras, enquanto o termo interculturalidade, segundo a própria autora, está dentro do "universo do multiculturalismo". Sua especificidade está em possibilitar o diálogo entre distintos grupos socioculturais, sendo assim, a interculturalidade permite intersecções.

Candau cita o trabalho da professora Catherine Walsh que aponta três concepções principais de educação intercultural na América Latina, quais sejam: relacional, funcional e crítica. Nas palavras da autora:

1) Interculturalidade relacional: "refere-se basicamente ao contacto e intercâmbio entre culturas e sujeitos socioculturais. Esta concepção tende a reduzir as relações interculturais ao âmbito das relações interpessoais e minimiza os conflitos e a assimetria de poder entre pessoas e grupos pertencentes a culturas diversas". (...)

2) Interculturalidade funcional: "a interculturalidade é assumida como estratégia para favorecer a coesão social, assimilando os grupos socioculturais subalternizados à sociedade hegemônica". (...)

3) Interculturalidade crítica: "Trata-se de questionar as diferenças e desigualdades construídas ao longo da história entre diferentes grupos socioculturais, etnicorraciais, de gênero, orientação sexual, entre outros" (...) (CANDAU, 2011b, p. 114-115).

Candau (2015) afirma que se situa no último grupo, na perspectiva da Interculturalidade Crítica. É desta visão e percepção que também parte a concepção de interculturalidade abordada neste artigo.

\section{GÊNERO, SEXUALIDADE E EDUCAÇÃO}

Tendo como perspectiva o campo da Interculturalidade, assim como apresentado por Fleuri (2003) e Candau (2015, 2011), faremos nosso recorte nas questões que envolvem gênero e educação, a partir da percepção de que as questões envolvendo gênero e sexualidades têm sido bastante discutidas no âmbito da educação brasileira. Houve, inclusive, uma ênfase maior, no ano de 2015, visto que as redes municipais e estaduais de educação se empenharam na construção de Planos Municipais e Estaduais de Educação visando acrescentar e/ou retirar elementos para a construção do Plano Nacional de Educação (PNE) que estará em vigor nos próximos 10 anos e, neste sentido, houve acaloradas discussões nos 
conselhos municipais e estaduais sobre a inclusão ou não das questões de gênero no planejamento das Redes Educacionais.

Vale ressaltar que, segundo Louro (2014), durante muito tempo a temática acerca de gênero e sexualidade ficou restrita às aulas de Ciências, que tinham um caráter biológico da estrutura e funcionamento do corpo humano, e/ou de Educação Sexual. Esta última, sempre gerando discussões, pois vários grupos questionavam a presença da disciplina no ambiente escolar, um primeiro, porque não acreditava ser função da escola discutir essas questões; o segundo grupo questionava se seria necessário haver uma disciplina específica para discutir gênero e sexualidade, ou se a discussão deveria ter um caráter multidisciplinar e/ou transversal, envolvendo todos os atores da comunidade e todas as disciplinas do currículo.

Diante da questão exposta, temos, atualmente, em nossa sociedade, dois grupos principais, com posições opostas acerca da discussão de gênero e sexualidade na escola, o primeiro deles defende que este é um debate presente em nossa sociedade e como a escola não está desvinculada desta, é preciso discutir questões como: assédio sexual contra as mulheres, violência contra as mulheres, homofobia, transexualidade, homossexualidade, doenças sexualmente transmissíveis, dentre outras questões relacionadas ao gênero e à sexualidade. Por outro lado, há um grupo que acredita que essas discussões devem ficar a cargo da família, visto que há questões morais e religiosas que cada uma resolve à sua maneira.

Como citado, anteriormente, muitas entidades protestaram para que os planos municipais e estaduais não abordassem a temática do gênero e da sexualidade. Por outro lado, várias organizações e movimentos organizados de mulheres, transgêneros e homossexuais, assim, como de educadores, manifestaram-se a favor da inclusão da questão de gênero nos planos, alegando que o tema visa combater as práticas preconceituosas e discriminatórias iniciadas na infância, visto que coloca como tarefa da escola discutir com os alunos a equidade de gênero, levando-se em conta que, mesmo que de forma inconsciente - pois existe toda uma carga de discriminação histórica na sociedade contra as mulheres, transgêneros e homossexuais - o preconceito, a desigualdade e o machismo são reproduzidos.

Uma das petições que solicitava a inclusão da igualdade de Gênero no PNE foi criada no site de Petições Avaaz $^{2}$ e foi enviada ao Congresso Nacional, um dos trechos desta petição afirmava:

\footnotetext{
${ }^{2}$ Segundo o site Avaaz.org: "A Avaaz é uma comunidade de mobilização online que leva a voz da sociedade civil para a política global”. (Disponível em: 〈http://www.avaaz.org>. Acesso em: 01 mar. 2016.
} 


\begin{abstract}
A Escola precisa ensinar à criança não apenas a ler, escrever, fazer contas, aprender geografia, ciências, mas também ensiná-la como ser uma pessoa conscienciosa, adepta da cultura da tolerância. Algumas sugestões que serão tratadas de forma lúdica e na linguagem correta para a criança: Abolir os estereótipos de gênero que são as representações perpetuadas em nossa sociedade sobre o que um Homem deve ou pode fazer de um lado; o que a Mulher deve ou pode fazer do outro. Lembrando que fica o Homem em evidente vantagem. Exterminar os papéis sociais de gênero que englobam os comportamentos ao longo da história, que valorizam certas atividades como sendo de homem e outras como de mulher. Extinguir - através da conscientização - a discriminação indireta. Acabar com os termos e linguagem que são paradigmas das desigualdades como: o emprego do gênero masculino para incluir homens e mulheres $(2015, \mathrm{~s} / \mathrm{p}$.).
\end{abstract}

Diante do debate e das manifestações ocorridos, o Ministério da Educação, junto com o Conselho Nacional de Educação, elaborou uma nota pública, em 01 de setembro de 2015, manifestando-se favorável à discussão de gênero nas escolas brasileiras. A nota defende a diversidade cultural e destaca a defesa da diversidade de gênero. Ainda, segundo o documento:

$\mathrm{O}$ ato de universalizar direitos, mormente na educação, implica identificar e nominar, em situações concretas do cotidiano da existência humana, as singularidades, especialmente em formações sociais que, tradicionalmente as desconheceram, seja por via da omissão, seja por via da generalização que não lhe dá cobertura. [...] Em suma, o CNE considera que a ausência ou insuficiência de tratamento das referidas singularidades fazem com que os planos de educação que assim as trataram sejam tidos como incompletos e que, por isso, devem ser objeto de revisão (BRASIL, 2015, s/p.).

O fato levou o debate para o seio da sociedade, ultrapassando os muros da escola. Entendemos que este tipo de debate, apesar de posições que enfatizam a universalidade, a normatização e a padronização dos indivíduos, mostra que a presença dos movimentos sociais fortes e questionadores, que defendem a diversidade e a interculturalidade, pode ser um caminho de transformação e de busca de novas concepções e deslocamentos, que levam a um pensar outro, que não o hegemônico. Nas palavras de Louro (2014, p. 124):

Escolas e academias, em suas práticas, experimentam continuidades e descontinuidades, realizam deslocamentos e, eventualmente, rupturas. As denúncias, as questões e as críticas feministas, bem como aquelas vindas dos Estudos Culturais, dos Estudos Negros, dos Estudos Gays e Lésbicos também estão produzindo efeitos. Assim sendo, ainda que de formas talvez tímidas, vemos hoje em escolas brasileiras experiências e iniciativas que buscam subverter as situações desiguais de classe, raça, gênero, etnia - vividas pelos sujeitos.

Conforme exposto por Louro (2014), as experiências pedagógicas que podem ser denominadas interculturais, nas escolas brasileiras, ainda são tímidas, mas vêm crescendo e 
ganhando apoio dos grupos sociais organizados que, muitas vezes, cobram uma posição mais crítica das instituições de ensino, conforme a petição supracitada, objetivando a diversidade cultural nessas instituições.

Outro fator que aponta para uma abertura para a interculturalidade em relação às questões de gênero refere-se ao último Exame Nacional do Ensino Médio (Enem), realizado em outubro de 2015. Este exame avalia os estudantes do terceiro ano do Ensino Médio de todo o país. Assim, na prova da Área de Linguagens, Códigos e suas Tecnologias, foi apresentada uma questão em que se discutia uma frase da pensadora feminista Simone de Beauvoir, qual seja, "Não se nasce mulher, torna-se mulher". A questão apontava para a discussão de que ser homem ou ser mulher perpassa por construções sociais e culturais, o que é o grande mote dos movimentos de gênero em todo o mundo, cuja pensadora francesa é uma referência importante.

O tema da prova de redação desta mesma edição do exame foi "A persistência da violência contra a mulher na sociedade brasileira", apontando para a necessidade de tratar dessas questões no seio das instituições de ensino. Visto que, são temas da atualidade e não podem ser simplesmente ignorados.

\section{Cinema, Educação e Gênero}

Entendendo que, da mesma maneira que a escola vem, mesmo que timidamente, se abrindo para as discussões que envolvem as diferentes identidades culturais, numa perspectiva intercultural, fica evidente, também, a abertura que é dada para o trabalho com as mídias. Nas últimas décadas, existe uma maior aproximação entre educação e mídia, essa aproximação ficou consolidada oficialmente em 1982 com a Declaração de Grünwald, um documento assinado, na referida cidade alemã, por 19 países na perspectiva de educar os alunos para os meios (ou para as mídias).

Educar para as mídias é pensar um espectador crítico diante do que os meios de comunicação de massa oferecem cotidianamente, é entender que a escola não pode ignorar o quanto os meios de comunicação estão presentes no cotidiano de seus alunos e da sociedade em geral. Para Guillermo Orozco, um dos estudiosos do campo dos Estudos da Comunicação latino-americanos, é importante, a escola ter um papel de destaque na mediação entre os alunos e os Meios de Comunicação de Massa (MCM). Para o autor: 
É necessário exercer explicitamente uma mediação que oriente a aprendizagem dos estudantes fora da aula, que permita recontextualizá-la, sancioná-la sob diversos critérios éticos e sociais, permitindo aproveitar o que de positivo oferecem os MCM, capitalizando para a escola a informação e as demais possibilidades que esses meios nos trazem. (OROZCO, 1997, p. 63).

Desta forma, ao se referir ao campo da comunicação/educação, ou Educomunicação, Bacega (2009, p. 20) afirma:

Por isso, comunicação/educação inclui, mas não se resume a, educação para os meios, leitura crítica dos meios, uso da tecnologia em sala de aula, formação do professor para o trato com os meios, etc. Tem, sobretudo, o objetivo de construir a cidadania, a partir do mundo editado devidamente conhecido e criticado. Nesse campo cabem: do território digital à arte-educação, do meio ambiente à educação a distância, entre muitos outros tópicos, sem esquecer os vários suportes, as várias linguagens - televisão, rádio, teatro, cinema, jornal, cibercultura etc. Tudo percorrido com os olhos da congregação de agências de formação: as escola e os meios, voltados sempre para a construção de uma nova variável histórica.

Neste sentido, acreditamos que a escola é um lugar propício, não só para visualização das mídias, mas para análise e debate em torno delas, perspectivando uma relação entre escola-mídia que seja de complementaridade, permitindo à escola um olhar de rearticulação em relação aos meios de comunicação.

Em relação ao cinema, Balestrine e Soares (2012) propõem algumas questões: “O que pode um filme? O que se pode fazer com um filme?” (2012, p. 91). Segundo as autoras: "Acreditamos que o cinema, como uma arte e uma forma específica de linguagem, possui potência para romper com e ressignificar determinadas construções sociais já existentes" (BALESTRINE e SOARES, 2012, p. 91). Ou ainda:

(...) não há como saber o que um filme pode, afinal, fazer conosco e vice-versa - o que nós podemos fazer com um filme. É na relação que estabelecemos com a imagem que se nos coloca que algo pode (ou não) acontecer (p. 91).

Ainda, nesta mesma perspectiva, Leite considera que:

A cultura da mídia fornece material com que muitas pessoas constroem o seu senso de classe, de etnia e raça, de nacionalidade, de sexualidade, de nós e eles. Auxilia a modelar a visão prevalente de mundo e os valores mais profundos: define o que é considerado bom ou mau, positivo ou negativo, moral ou imoral. A cultura da mídia tem por objetivo a grande audiência; por isso, deve ser eco de assuntos e preocupações atuais, sendo extremamente tópica e apresentando dados da agenda social contemporânea (LEITE, 2003, p. 07). 
Ellsworsth (2001), ao tratar das relações entre educação e cinema, em texto que trata dos modos de endereçamento, afirma que os filmes imaginam determinado público, mas "os públicos não são todos iguais e que os diferentes públicos fazem leituras diferentes e extraem prazeres diferentes, e muitas vezes, opostos, do mesmo filme” (ELLSWORSTH, 2001, p. 33).

Vale ressaltar que o cinema é representação e a representação cinematográfica é resultado de convenções específicas de determinado tempo e espaço e estão ligadas às posições que os sujeitos ocupam na trama discursiva, ou seja, a maneira com que roteiristas, produtores e diretores interpretam determinado tempo e espaço e transportam isso para a narrativa audiovisual. Vale lembrar que, entre o pensar, o escrever e o executar uma produção audiovisual há inúmeros passos e atores sociais envolvidos e a interpretação do real passa pela interpretação desses atores, portanto, a representação será sempre o que estes atores interpretaram do movimento inicial.

Levar esta discussão para o universo escolar é abrir-se para uma educação que vai além da reprodução de valores, é entender que se deve educar para a crítica às reproduções culturais. É necessário entender que, segundo o Dicionário de Conceitos-chave em Estudos de Comunicação e Cultural, o conceito de reprodução cultural está intimamente ligado ao de Representação, pois indica que: “A reprodução cultural é, portanto, uma tentativa de naturalizar ou legitimar a autoridade social dos interesses dominantes - entendidos usualmente em termos de classe/raça/gênero (sexual)" (2001, p.215). Dessa forma, podemos entender a Representação como uma tentativa de reproduzir uma determinada realidade e mostrá-la como a única interpretação possível desta realidade. Questionar que a Representação é apenas uma das formas de ver o mundo, e não a única, é certamente papel do educador que acredita numa educação intercultural crítica, tal como definimos no início deste artigo.

Estas afirmações nos permitem perceber o discurso cinematográfico como algo que provoca sentidos novos em quem o assiste, mas que pode provocar novidades em quem o produz, visto que, o público de cinema é capaz de exigir novas formas de representações, pois os produtores de filmes têm sempre a necessidade de tentar atender a determinado público, e a perspectiva da indústria cinematográfica é a de que este público seja o maior possível. Dessa maneira, o cinema é um artefato cultural que produz sujeitos e é produzido por eles. Ou, como diz Martín-Barbero (2013), em epígrafe que abre este artigo, nós podemos aprender com o cinema: "Não se ia ao cinema para sonhar; ia-se para aprender" (p. 235). 
Neste sentido, o audiovisual na sala de aula cria possibilidades de ensinar a partir da fruição e/ou do entretenimento e, ao mesmo tempo, é uma forma de militância/ativismo e também pode servir para formar espectadores mais conscientes da repercussão dos artefatos culturais na sociedade. Segundo Ferrari e Castro (2012, p. 13):

\begin{abstract}
A incapacidade de separar a Educação de outros campos de conhecimento e das imagens de forma geral abriu a possibilidade de novas áreas de investigação, não somente no campo das visualidades, mas também, na Formação Docente, no Currículo, nos Estudos de Gênero e Sexualidade, no Processo de Subjetivação. Isso porque falar de imagem, de produção de imagens, de significação e representação visual supõe incluir o espectro das Artes e da Cultura Visual no âmbito dos processos educativos ancorados em contextos de subjetivação.
\end{abstract}

Entendemos ainda que o cinema pode não só ensinar, mas nos leva a refletir, criticar e fazer uma leitura de mundo, a partir das imagens vistas, das falas ouvidas e da maneira como o roteiro é construído. Assistir e comentar, discutir ou pensar um filme, em sala de aula, pode contribuir para a formação humana, sendo assim, é um elemento importante na contribuição para uma educação intercultural crítica.

Há vários estudos que ligam o audiovisual à educação, desde aqueles que tratam de temáticas comuns à educação, tais como: “o modo como infância, escola, professores/as, relações professor/aluno, sexualidade, juventude, etc. são representados em filmes [...]" (DUARTE, 2009, p. 87), até outros que abordam temáticas variadas e podem ser levados para a sala de aula na perspectiva de problematizar a maneira como, por exemplo, as mulheres são representadas nos filmes.

Nesta última perspectiva, vale citar os trabalhos de Louro (2008 e 2013), nos quais a autora analisa filmes de Hollywood, produzidos após a segunda guerra mundial, e que foram sucesso de público tanto nos Estados Unidos quanto em outros países, incluindo o Brasil. Nos artigos, a autora analisa os filmes procurando perceber como se dá a representação de gênero/sexualidade. Nas palavras de Duarte (2009, p. 90):

Para Guacira Louro, a indústria de Hollywood, conduzida desde o início por homens brancos ocidentais, constrói suas imagens a partir da ótica masculina, branca, heterossexual, de classe média e, usualmente, judaico-cristã, que sempre se apresentou como universal. Ela acredita que os filmes produzidos desse modo ajudaram a construir concepções de gênero, sexualidade, classes sociais em diferentes sociedades, atuando como uma "pedagogia cultural" que ultrapassou fronteiras simbólicas e geográficas, mas que enfrentou a reação de políticas de identidade divergentes desta, que também se expressam por meio do cinema. 
O que Louro (2008 e 2013) defende é que existem novas possibilidades de ver estes filmes, a partir do que nós estamos chamando de ótica intercultural, levando-se em conta a necessidade de discutir e problematizar as representações ou reproduções culturais do audiovisual na sala de aula. Além disso, Louro (2008), ainda, aponta para uma ampliação das representações de identidades de gênero no cinema, que segundo ela perpassam, inclusive por discursos e representações construídos "no interior dos movimentos sociais ou dos grupos intelectuais das chamadas 'minorias' sexuais” (p. 87).

Segundo Louro: “(...) o cinema, como tantas outras instâncias, pluraliza suas representações sobre sexualidade e gêneros. Por toda a parte (e também nos filmes) proliferam possibilidades de sujeitos, de práticas de arranjos e, como seria de se esperar, proliferam questões" (LOURO, 2008, p. 94).

Entendemos que propor discussões a partir das visualizações de filmes no ambiente escolar podem contribuir para entendermos que há diversas formas de ser humano, que é necessário superar as dicotomias homem/mulher, normal/anormal, e que é preciso romper com a discriminação e o preconceito. "De qualquer modo, é inegável que se multiplicaram e diversificaram, no cinema e em outras instâncias culturais, as representações sobre a sexualidade (e sobre a homossexualidade) “(LOURO, 2008, p. 87). E isso, certamente, só contribui para uma aproximação das mídias e do audiovisual com a educação intercultural crítica.

\section{CONSIDERAÇÕES FINAIS}

Acreditamos que, a partir do exposto pelos estudos de Louro (2008, 2013 e 2014) e outros autores como Ferrari e Castro (2013), Balestrin e Soares (2012), Duarte (2009) e Leite (2003) é possível tratar das concepções de gênero e diversidade a partir do audiovisual. Mais que isso, acreditamos na possibilidade de visualização de filmes para a crítica às reproduções culturais, intervindo de maneira efetiva para a construção de um olhar menos hegemônico nas relações de gênero e sexualidade em nossa sociedade. A partir dessas noções e discussões, é possível caminharmos para a equidade entre os gêneros a partir de uma prática pedagógica feminista.

Dessa forma, recomendamos que estas questões sejam trabalhadas em sala de aula, entendemos que abordar as questões envolvendo gênero, a partir do cinema, pode fazer com 
que o aluno aprenda de maneira menos ortodoxa, ou seja, o ensino-aprendizagem pode ser dar a partir da visualização de filmes, debate acerca dos filmes assistidos, o que traria um olhar mais lúdico à temática de gênero.

O trabalho com o cinema na sala de aula pode acontecer de maneira transdisciplinar, envolvendo vários professores e com propostas de atividades para várias disciplinas ou áreas de conhecimento, ou até mesmo, uma única disciplina com uma proposta de atividade envolvendo aquela disciplina específica. Acreditamos que, esta segunda opção de trabalho é exequível, mas não é a ideal, visto que é importante que todos os atores da escola envolvamse no trabalho com as temáticas envolvendo gênero, desta forma, a escola estaria passando uma visão institucional do assunto, o trabalho ganharia mais peso e maior densidade.

No caso de uma atividade transdisciplinar, por exemplo, é possível visualizar filmes cuja temática, seja, por exemplo, a luta das mulheres pelo voto. Neste caso, para ilustrar nosso exemplo, sugerimos o filme As Sufragistas, uma produção do Reino Unido que foi lançado no Brasil no final de 2015 e trata da luta das mulheres, no início do século XX, no Reino Unido, pelo direito ao voto. O filme permite uma série de discussões envolvendo todas as disciplinas do currículo escolar e aponta para um trabalho de reflexão, construção de textos, pesquisas sobre os diversos movimentos por direitos femininos ao redor do mundo, podendo, inclusive, ampliar para outras lutas femininas, tais como: o divórcio, a escolha pelo casamento ou não, a escolha pela maternidade, a presença de mulheres em profissões consideradas masculinas, a pouca presença de mulheres em determinadas áreas das ciências e das pesquisas, as discussões em torno do direito ao aborto e outras.

No caso do trabalho com uma única disciplina, é possível, a partir da visualização dos filmes, a criação de textos de discussão, resenhas, blogs, por exemplo, ainda na área de linguagens, é possível a promoção de debates, júris simulados e outras atividades que possibilitarão a perspectiva de um aluno-espectador crítico diante do audiovisual, entendemos que todas estas atividades podem contribuir para uma formação cidadã que ultrapasse os muros da escola.

Entendemos, ainda, que abordar estas questões na sala de aula é uma forma de combater práticas discriminatórias que apontam para formas e estereótipos do que é ser menina e do que é ser menino que se iniciam na infância e perpassam por toda a vida, e que envolvem, inclusive, a violência que atinge prioritariamente a mulheres, homossexuais, transexuais e transgêneros. 


\title{
GENDER, SEXUALITY AND THE IMPORTANCE OF INTERCULTURAL PEDAGOGICAL PRACTICES
}

\begin{abstract}
The present article aims to discuss intercultural pedagogical practices from the perspective presented by Fleury (2003) and Candau (2015, 2011). We will focus on matters involving Gender and Education, from the perception that it has been a widely discussed theme. The topic was highlighted in 2015, during which the National Education Plan (PNE, in Portuguese) was discussed for the next ten years and was emphasized due to antagonist positions regarding its inclusion on the PNE. In this article we will emphasize the practices within the media in education, dealing specifically with cinema, and the discussions of gender and sexuality in educational contexts. In order to contribute with the discussion, we will incorporate authors who deal with relationship between communication and education, such as Orozco (1997), Martin-Barbero (2013), Bacega (2009) and others. In the discussion regarding cinema, education, gender and sexuality we will attain to Louro (2014, 2013, 2008), Duarte (2009), Ferrari and Castro (2012), besides other scholars who handle the connections between media-sexuality-gender-education.
\end{abstract}

Keywords: Intercultural Education; Media; Sexuality; Gender; Cinema

\section{GÉNERO, SEXUALIDAD Y LA IMPORTANCIA DE LA EDUCACIÓN INTERCULTURAL PRÁCTICAS}

\begin{abstract}
Resumen
Este artículo tiene como objetivo discutir las prácticas de enseñanza intercultural desde la perspectiva presentada por Fleuri (2003) y Candau (2015, 2011). Haremos nuestro recorte sobre temas relacionados con el género y la educación, desde la percepción de que este ha sido un tema muy discutido. La cuestión fue destacada en 2015, en la que se discutió ampliamente el Plan Nacional de Educación (PNE, en portugués) para los próximos diez años y que llegó a la fama en posiciones más antagónicas en función de su inclusión en el PNE. En este artículo, nos centraremos en las prácticas de los medios de comunicación en la educación,
\end{abstract}


abordando específicamente el cine de género y las discusiones y la sexualidad en las escuelas. Para contribuir a la discusión que tendremos autores sobre la relación entre la comunicación y la educación, como Orozco (1997), Martín-Barbero (2013), Bacega (2009) y otros. La discusión entre el cine, la educación, el género y la sexualidad en la mantendrá a Louro (2014, 2013, 2008), Duarte (2009), Ferrari y Castro (2012), y otros estudiosos que se ocupan de la relación entre medios-sexualidad-género-educación.

Palabras clave: Educación Intercultural; Medios; Sexualidad; Género; Cinema

\section{REFERÊNCIAS}

AS SUFRAGISTAS. Direção: Sarah Gavron. Roteiro: Abi Morgan. Elenco: Elenco: Carey Mulligan, Helena Bonham Carter, Meryl Streep, Ben Whishaw, Brendan Gleeson, Romola Garai , Anne-Marie Duf. Reino Unido: Universal Pictures. 106 min., 2015.

BACEGA, Maria Aparecida. Comunicação/Educação e a construção de nova variável histórica. In: Comunicação \& Educação. Ano XIV, n. 3. São Paulo, set./dez. 2009, p. 19-28.

BALESTRIN, P. A.; SOARES, R. "Etnografia de tela": uma aposta metodológica. IN: MEYER, Dagmar Esterman. PARAÍSO, Marlucy Alves (organizadoras). Metodologia de pesquisa pós-críticas em Educação. Belo Horizonte, Mazza Edições, 2012. p. 87-10.

BRASIL. Ministério da Educação/Conselho Nacional de Educação. NOTA PÚBLICA às Assembleias Legislativas, à Câmara Legislativa do DF, às Câmaras de Vereadores, aos Conselhos Estaduais, Distrital e Municipais de Educação e à Sociedade Brasileira. Brasília, 1 Set. 2015.

CANDAU, Vera Maria. Educação em direitos humanos e diferenças culturais: questões e buscas. In: Diferenças culturais e educação: Construindo Caminhos. CANDAU, Vera Maria (Org.). Rio de Janeiro: 7 Letras, 2011. p. 13-34.

CANDAU, Vera Maria. Escola, Didática e Interculturalidade: Desafios Atuais. In: Didática Critica Intercultural: aproximações. CANDAU, Vera Maria.(Org.). Petrópolis: Vozes, 2015, v. 1, p. 107-138.

GRUNWALD Declaration on Media Education. Federal Republic of Germany, 22 January 1982. Disponível em:

< http://www.unesco.org/education/pdf/MEDIA_E.PDF>. Acesso em: 01 de Mar. 2016.

DUARTE, Rosália. Cinema e Educação. 3 Ed. Belo Horizonte: Autêntica, 2009.

ELLSWORTH, Elisabeth. Modo de endereçamento: uma coisa de cinema; uma coisa de educação. In: Nunca fomos humanos - nos rastros do sujeito. SILVA, Tomaz Tadeu (org.). Belo Horizonte: Autêntica, 2001. p. 07-77. 
FERRARI, A.; CASTRO, R. P. de. Política e poética das imagens: implicações para o campo da educação. In: FERRARI, A. CASTRO, R. P. de. (organizadores) Política e poética das imagens. Juiz de Fora. Ed.UFJF, 2012. p. 12-17.

FLEURI, Reinaldo Matias. Intercultura e Educação. In: Revista Brasileira de Educação. Maio/Jun/Jul/Ago, 2003, n.23, p. 16-35.

LEITE, Sidney Ferreira. O cinema manipula a realidade?. São Paulo: Paulus, 2003.

LOURO, Guacira Lopes. Gênero, sexualidade e educação: uma perspectiva pósestruturalista. 16. Ed. Petrópolis, RJ: Vozes, 2014.

LOURO, Guacira Lopes. Destemidos, bravos, solitários - a masculinidade na versão western. In: Bagoas. n. 10, 2013 , p. 171-182. Disponível em:

<http://periodicos.ufrn.br/bagoas/article/download/5382/4397>. Acesso em: 14 de Out. 2015.

LOURO, Guacira Lopes. Cinema e sexualidade. In: Educação e Realidade. Porto Alegre. V. 33, n. 1. Jan/jun.2008, p. 81-97.

MARTÍN-BARBERO, Jesús. Dos meios às mediações: comunicação, cultura e hegemonia. Trad. Ronald Polito e Sérgio Alcides. 7 ed. Rio de Janeiro: Editora UFRJ, 2013.

OROZCO, Guillermo. Professores e Meios de Comunicação: Desafios e Estereótipos. In: Comunicação \& Educação, São Paulo, Set./Dez. 1997, p. 57-68.

O'SULIVAN, T.; HARTLEY, J.; SAUNDERS, D.; MONTGOMERY, M.; FISKE, J. Conceitos-chave em Estudos de Comunicação e Cultura. Trad. Margarete Griesse e Amós Nascimento. Piracicaba: Editora UNIMEP, 2001.

PETIÇÃO Pública: Congresso Nacional: Inclusão da Igualdade de Gênero no PNE (Plano Nacional de Educação). Disponível em:

$<$ http://professoraalice.jusbrasil.com.br/artigos/121814529/inclusao-da-igualdade-de-generono-plano-nacional-de-educacao>. Acesso em: 25 de Jan. 2016.

Data de recebimento: $25 / 01 / 2016$

Data de aceite: 01/03/2016 